OPEN ACCESS

Edited by:

Shengxiang Ren,

Tongji University, China

Reviewed by:

Luca Cantini,

Erasmus Medical Center, Netherlands

Guozhu Ye,

Institute of Urban Environment (CAS),

China

${ }^{*}$ Correspondence:

Hui Zhao

zhaohui@dmu.edu.cn

Specialty section:

This article was submitted to

Thoracic Oncology,

a section of the journal

Frontiers in Oncology

Received: 09 May 2021

Accepted: 15 July 2021

Published: 06 August 2021

Citation:

Li C and Zhao H (2021)

Tryptophan and Its Metabolites in Lung Cancer: Basic Functions

and Clinical Significance.

Front. Oncol. 11:707277.

doi: 10.3389/fonc.2021.707277

\section{Tryptophan and Its Metabolites in Lung Cancer: Basic Functions and Clinical Significance}

\author{
Chenwei $\mathrm{Li}^{1}$ and Hui Zhao ${ }^{2 *}$ \\ ${ }^{1}$ Department of Respiratory Medicine, The Second Affiliated Hospital of Dalian Medical University, Dalian, China, \\ ${ }^{2}$ Department of Health Examination Center, The Second Affiliated Hospital of Dalian Medical University, Dalian, China
}

Lung cancer is the most lethal malignancy worldwide. Recently, it has been recognized that metabolic reprogramming is a complex and multifaceted factor, contributing to the process of lung cancer. Tryptophan (Try) is an essential amino acid, and Try and its metabolites can regulate the progression of lung cancer. Here, we review the pleiotropic functions of the Try metabolic pathway, its metabolites, and key enzymes in the pathogenic process of lung cancer, including modulating the tumor environment, promoting immune suppression, and drug resistance. We summarize the recent advance in therapeutic drugs targeting the Try metabolism and kynurenine pathway and their clinical trials.

Keywords: tryptophan, lung cancer, kynurenine pathway, IDO, TDO

\section{INTRODUCTION}

Lung cancer (LC) is one of the most common malignancies worldwide and has a high mortality rate (1). Previous studies have shown that lung carcinogenesis is attributed to the gain-functional mutation of several cancer-associated genes, including the epidermal growth factor receptor (EGFR), Kirsten rat sarcoma viral oncogene homolog (KRAS), and v-raf murine sarcoma viral oncogene homolog B1 (BRAF) (2-4). Actually, therapeutic drugs targeting these molecules have been demonstrated to prolong the survival of LC patients, particularly for non-small cell lung cancer (NSCLC) patients. However, therapeutic efficacy of these drugs is limited due to rapid development of drug resistance in LC patients (4-6). Therefore, other effective treatments are urgently needed. Currently, cancer has been thought not to be a genetic disease, rather than a metabolic disease, which is associated with tumor immune escape $(7,8)$. It is well known that tumor cells usually undergo aerobic glycolysis for their glucose metabolism, known as the Warburg effect (9). Moreover, extensive studies have revealed that alternations in metabolisms are not only for glucose, but also for amino acid, lipid, nucleotide, and others in cancer (10). Notably, tryptophan (Try) metabolism is a particularly compelling physiological context in LC because of its complex and multifaceted effect on LC cells and cancer-associated cells in immune escape (11).

Try cannot be synthesized directly by the human body and has the lowest levels in the human body among 20 essential amino acids such that it depends on food protein. Similar to other essential amino acids, Try is essential for biosynthesizing cellular protein and formatting cytoskeleton (12). In the circulation, most Try binds to albumin for transportation and only $10 \%-20 \%$ of it remain free amino acid $(13,14)$. The free Try is mainly degraded through the kynurenine $(\mathrm{KYN})$ pathway and is 
metabolized to form serotonin or other metabolites (15). Try plays a significantly physiological role in synthesizing proteins. However, the metabolic formation of serotonin and the KYN pathway-mediated metabolism, together with the lack of its endogenous production, may make Try shortage that can impair the protein synthesis. In the KYN pathway, Try is firstly converted to formyl-kynurenine, which is rapidly degraded to KYN by key enzymes of indoleamine-pyrrole 2,3dioxygenase (IDO)1, IDO2, and tryptophan 2,3-dioxygenase (TDO), particularly by IDO1 $(14,16)$. Next, KYN is catalyzed into a series of metabolites, including anthranilic acid (AA), kynurenic acid (KA), xanthurenic acid (XA), 3hydroxyanthranilic (3-HAA), quinolinic acid (QA), and NAD+ (17). In the lung, Try degradation is mainly catalyzed by IDO1 because IDO1 is constitutively expressed in many organs while TDO is predominantly expressed in the liver (18). Previous studies have shown that most Try metabolites in the KYN pathway are associated with the development of many diseases, including cancer. Actually, the IDO1-related Try metabolites are associated with lung cancer development $(19,20)$. This review aims to summarize the research advance in how Try and its metabolites contribute to the development and progression of LC.

\section{THE EXPRESSION AND BIOLOGICAL FUNCTIONS OF TrY METABOLITES IN LC}

\section{Try and Its Metabolites in LC}

A previous study has indicated that circulating Try levels decrease in patients with lung, gastric, colorectal, breast, and prostate cancer (21). Recent studies using liquid chromatography mass spectrometry (LC-MS) have found that plasma Try and XA levels decrease and 3-HAA increases in 19 NSCLC patients, relative to 10 non-tumor healthy controls $(22,23)$. Similarly, high-performance liquid chromatography-fluorescence detection (HPLC-FD) or gas chromatography mass spectrometry (GC-MS) analyses reveal that the concentrations of serum Try in LC patients are significantly lower than that in the controls $(24,25)$. Moreover, patients with lung adenocarcinoma (LADC) tend to have lower serum Try concentrations than those with lung squamous carcinoma (LSCC), which may be related to its regulatory function in the proliferation and metastasis of different types of cancers (24). However, there is no significant difference in the levels of serum Try during the progression of lung cancer. Accordingly, the levels of serum or plasma Try may be useful for the diagnosis of LC with a specificity of $>92 \%$ (24). Interestingly, a study reveals that cisplatin-resistant LC cells consume more Try than nonresistant cells (26), suggesting that Try levels may be associated with the development of drug resistance in LC cells. However, how the levels of circulating Try are associated with levels of Try in the tumor microenvironment remains to be investigated.

The decrease in circulating Try may be attributed to several reasons. First, the enhanced expression and activity of Trymetabolizing enzymes in LC patients can promote Try metabolism, decreasing the levels of Try in the circulation and tumor (27). Second, LC patients may have malnutrition and poor digestion/absorption so that they may intake less Try from foods (24). Last, over-consumption of Try-contained foods may disorder Try metabolism, especially in advanced stage of lung cancer $(24,28)$ because Try is an essential component for cytoskeleton and protein synthesis in LC.

Decreased circulating Try is a crucial metabolic feature in LC patients. Accordingly, Try levels may combine with other metabolic molecules for diagnosis of LC. Actually, the levels of serum Try, alanine, valine, isoleucine, histidine, and ornithine have a diagnostic value for NSCLC with an area under the receiver-operator characteristic (ROC) of $>0.80$, and effectively discriminate neoplastic patients from healthy subjects $(29,30)$. LC patients display decreased levels of serum Try, threonine, citrulline, and histidine and increased proline, isoleucine, phenylalanine, and ornithine, leading to an area under curve (AUC) of 0.80 , but the Try metabolite profile does not distinguish different pathological types of LC $(29,31)$. Consistently, HPLC-FD analysis indicates that a combination of six metabolites [L-tryptophan, hypoxanthine, inosine, indoleacrylic acid, acylcarnitine C10:1, and lysoPC (18:2)] effectively separates NSCLC patients from non-tumor subjects with an AUC of 0.99 (32).

\section{ID01, IDO2, and TDO in LC IDO1}

The IDO1 is a key enzyme in the KYN pathway, particularly in the lung. Previous studies have detected IDO expression in tumor cells, blood vessels, stromal cells of NSCLC patients, as well as in dendritic cells (DCs) in the tumor environment and tumor-related lymph nodes in patients with LC (33). However, the function of IDO1 in endothelial cells has yet been understood (34). The expression of IDO promotes KYN accumulation, which may dilate blood vessels (35). Accordingly, it is possible that IDO1 deficiency may reduce vascular-related adverse reaction of some therapeutic drugs pharmacologically (35). Besides, IDO1 mRNA transcripts are upregulated in lung tissues (36) and the serum KYN : Try ratio (KTR), an indicative of IDO activity, is greater in LC patients than healthy subjects (37), supporting the notion that higher KTR is associated with increased risk for LC (38), especially for LSCC in heavy smokers, because AhR (aryl hydrocarbon receptor) activates the carcinogenesis pathway of benzo(a)pyrene $(\mathrm{BaP})$, a strong lung carcinogen derived from tobacco smoking (39). High levels of IDO1 expression can enhance LC cell invasion in vitro and distant metastasis into the brain, liver, and bone in vivo, while IDO1 inhibition attenuates their invasion and distant metastasis in rodents (40). Similarly, IDO1 inhibition also inhibits the lung metastasis of breast cancer and improves the survival of tumorbearing animals $(41,42)$. Furthermore, IDO1-deficient mice are partially resistant to cancer growth in a Lewis rat model of lung carcinoma (43).

The activity and expression of IDO1 are associated with diagnosis, prognosis, and therapeutic responses in LC (44-48). IDO1 activity may be a valuable biomarker for evaluating the response to immunotherapy, and its levels may help in choosing therapy for LC patients, who are sensitive to immunotherapy (49). 
Similarly, increased IDO1 activity is detected in LC patients, who initially respond to immune checkpoint inhibitors (ICIs) and later exhibit cancer progression, leading to a worse prognosis (44). Furthermore, increased IDO1 activity is closely associated with worse survival of NSCLC patients receiving explicit radiotherapy $(48,50)$. However, these studies were performed in small groups of patients. Therefore, further prospective studies with a larger population are necessary to validate the prognostic value of IDO1 activity in LC patients following radiotherapy. Interestingly, elevated IDO1 expression is associated with better outcome in lung adenosquamous carcinoma patients, especially for those after surgical resection of the tumor (51). The discrepancy may stem from different studying populations. While previous studies mainly focus on patients with unresectable LC and patients receiving chemotherapy or chemoradiation, this study centers on LC patients after radical surgery (51). It is possible that IDO1 activity may have different values in prognosis of different stages of LC following varying therapeutic strategies.

\section{IDO2 and TDO}

IDO2 and TDO are other key enzymes for Try degradation (52-55). Although the IDO1 and IDO2 genes are highly homologous at human chromosome 8 and tightly connected $(56,57)$, the IDO2 catalytic activity is much weaker than that of IDO1 in vitro and in vivo (58). Actually, there is no significant difference in the concentrations of plasma Try and KYN between wild-type and IDO2-deficient mice (59). Human TDO gene sequence has a low homology (16\%) with the IDO1, but their protein catalytic domains have a high similarity (60) and TDO is predominantly expressed in the liver (61). Similar to IDO1, upregulated IDO2 and TDO may be associated with immune escape in some types of tumors $(53,55,62$, 63). Previous studies have reported that TDO enhances the migration and invasion of glioblastoma and breast cancer cells in vitro and treatment with a TDO inhibitor significantly inhibits distant metastasis in mice (64-66). Furthermore, $\mathrm{IDO}^{-/-}$mice display a decreased tumor size compared with wild-type mice (67). Pharmacological inhibition of TDO reduces the number of lung tumor nodules in mice (68). Apparently, enhanced IDO2 and TDO expression and activity may promote the progression and metastasis of LC and their activity is indistinguishable (49). Similar to the function of IDO1, upregulated IDO2 expression is linked to worse prognosis in NSCLC (53). Therefore, IDO2 inhibitors may be valuable for targeting $\mathrm{LC}$ and IDO2 may be a biomarker for immunotherapy (69). Moreover, there is little information on whether IDO2 expression is associated with resistance to cisplatin in LC patients and what the value of IDO2 is in diagnosis and prognosis of LC $(26,63)$. Therefore, further studies are warranted to address these questions.

\section{Try METABOLITES AND IMMUNE ESCAPE IN LC}

The immune escape is a "hallmark of cancer" $(70,71)$. Tumor immune escape refers to the phenomenon, in which tumor cells can grow and metastasize by avoiding recognition and attack by the immune system through various mechanisms (72). Currently, IDO1 has been suggested to be important for immune escape of LC. First, upregulated IDO1 expression promotes the degradation of Try and the accumulation of its metabolites (such as KYN, 3-HAA and others) in LC. These metabolites act on various immune cells, including $\mathrm{T}$ cells (naive CD4+ T cells, Th17, and Treg), antigen-presenting cells (APC, DCs, and macrophages), and NK cells, and lead to immune escape. The promising mechanisms by which Try metabolites induce cancer immune tolerance and immunosuppression are summarized in Figure 1.

First, Try is an essential amino acid for immune cell proliferation, and Try depletion results in T-cell apoptosis, which is one major reason for cancer immunosuppression (73). The decreased Try levels can inhibit T-cell proliferation by activating general control over nonderepressible 2 (GCN2) kinase and suppressing the mTOR signaling, a target of rapamycin (74-76). The GCN2 is a serine/threonine kinase and can phosphorylate eukaryotic initiation factor 2a kinase (eIF2a) in the presence of low concentration of Try, inhibiting protein synthesis and $\mathrm{T}$ cell proliferation (74). Activated GCN2 can also promote the differentiation of naïve CD4+ T cells into Tregs $(16,74,77)$. Furthermore, GCN2 can alter the phenotype of DCs and macrophages $(75,76,78)$, making them prone to immunosuppression to promote tumorigenesis. In contrast, other studies argue that GCN2 is a sensor of amino acid starvation and its activation is not dependent on a low Try level, rather than deficiency in many amino acids $(79,80)$. Actually, T cells with GCN2 deficiency have similar activity to wild-type $\mathrm{T}$ cells in B16 melanoma-bearing mice (79), which contradicts the tumor promotion of GCN2. Apparently, there may be another mechanism that senses Try-deprived condition to regulate $\mathrm{T}$ cell immunity against tumor. The mTOR signaling appears to be a possible candidate $(81,82)$ because inhibition of mTOR complex 1 (mTORC1) can induce T-cell autophagy and anergy in the tumor microenvironment (83). Moreover, mTORC1 inhibition can also induce Treg cells to suppress anti-tumor immune responses (82).

Second, increased KYN can lead to immune tolerance by inhibiting $\mathrm{T}$ cell proliferation and inducing $\mathrm{T}$ cell apoptosis to promote tumor growth (38). The KYN is a ligand of AhR, and its activation promotes Treg cell differentiation that can directly inhibit anti-tumor immune responses, contributing to cancer immune escape $(77,84)$. The AhR activation can also direct DCs and macrophages toward an immune-suppressive phenotype (85-87). The AhR activation enhances IL-10 synthesis and secretion, and inhibits the IFN- $\beta$ signaling in DCs, but induces IL-10 and IFN- $\alpha$ production in NK cells, respectively. Consistently, higher frequency of Tregs is detected in mice bearing cisplatin-resistant tumors than those bearing cisplatinsensitive tumors (26).

Third, the downstream metabolites (such as 3-HAA and QA) of KYN can also induce T-cell apoptosis (88), contributing to immune tolerance. Recent studies have shown that QA can inhibit the proliferation of cancer-specific CD8+ cytotoxic T 


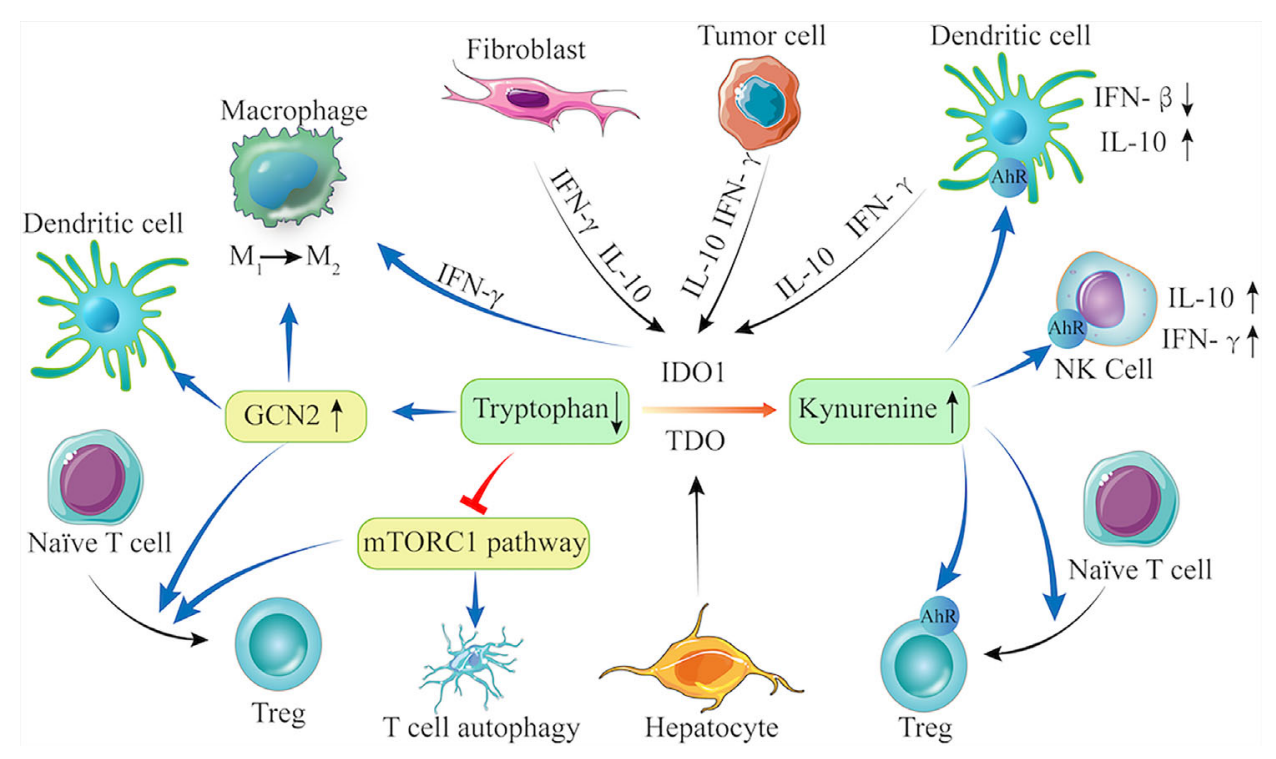

FIGURE 1 | The Try-IDO1/TDO-KYN pathway and immune escape. IDO1 is constitutively expressed in fibroblast, tumor cells, and DCs, and can be upregulated by IL-10 and IFN- $\gamma$, whereas TDO is only expressed in hepatocytes. When IDO1 and TDO are activated, they promote Try degradation and KYN accumulation. Try depletion can activate GCN2 and inhibit the mTORC1 signaling. The KYN can bind to AhR in NK cells, Tregs, and DCs. Therefore, the Try-IDO1/TDO-KYN pathway cooperatively modulates immune cells (e.g., DCs, macrophage, Treg, and T cells) to regulate anti-inflammatory cytokine production, leading to enhanced immunosuppression in the tumor microenvironment.

and NK cells to promote tumor growth (89). Furthermore, LC patients with lower plasma 3-HAA, the precursor of QA, benefit more from ICI treatment, suggesting that plasma 3-HAA levels may be a biomarker for predicting the response of LC patients to ICIs (23). The lower plasma 3-HAA may reflect less immunosuppression in patients because 3 -HAA can promote Treg responses to produce high levels of TGF- $\beta$ that decrease effector T-cell function, leading to immunosuppression (90). However, its precise mechanism in tumor immunity is not clear.

Next, IDO1 expression can be regulated by cytokines, such as IL-10 and IFN- $\gamma(91,92)$ while IDO1 inhibition can enhance Tcell proliferation and infiltration in the tumor environment and IL-2 production (93). Furthermore, IDO1 or IDO2 deficiency can modulate the tumor microenvironment by reducing KTR, enhancing immune cell infiltration and IFN- $\gamma$ production (67). TDO and IDO 2 act as the Try-metabolizing enzymes and can also promote Try degradation, resulting in immune regulation similar to IDO1. However, there are few reports and further studies are needed.

Last, IDO1 and TDO catalyze the production of several downstream Try metabolites, such as KYN (64, 84), KA (94), and XA (66), which can activate the AhR and may contribute to the immune modulation of IDO1 and TDO. Interestingly, KYN can directly bind and activate the AhR, with a high affinity at low picomolar levels (95). However, whether similar mechanisms also apply to other polar metabolites that activate the AhR, such as $\mathrm{KA}$, remains to be investigated. In addition, $\mathrm{AhR}$ can regulate IDO-related regulatory phenotype in DCs (96). Here, an autocrine IDO-KYN/AhR-IDO feedback loop may contribute to the immune modulation $(97,98)$.

\section{THE CLINICAL APPLICATIONS OF Try METABOLITES IN LC}

Enhanced IDO1 expression and activity can evade immunosurveillance and are associated with poor prognosis of LC. Therefore, inhibition of IDO1 may be an ideal strategy for intervention of LC. There are several direct IDO1 inhibitors available, including epacadostat and navoximod that neither directly kill tumor cells, nor spontaneously initiate an immune response (99). Unlike epacadostat, the Try mimetic indoximod (D-1MT, 1-methyl-D-tryptophan) is the first non-enzyme inhibitory drug that targets the IDO1 pathway and can inhibit lung tumor growth in vivo (100-102). Indoximod can directly act on immune cells by creating an artificially Try-related signal, relieving the IDO1-mediated immunosuppression (99). There are ongoing clinical trials that investigate anti-IDO1 agents as monotherapy or adjuvant therapies with other drugs for various solid tumors. The clinical trials of anti-IDO1 agents for different combination strategies, such as combination with ICIs, other immunomodulators, and chemotherapy, are summarized in Table 1.

Epacadostat, a small-molecule IDO1 inhibitor, was developed by Incyte and is being tested for its therapeutic efficacy and safety in an advanced stage of clinical trial (103). The phase I/II KeyNote 037/ECHO 301 trial to test the safety and efficacy of different doses of epacadostat combined with $200 \mathrm{mg}$ pembrolizumab (i.e., an anti-PD1 agent) every 3 weeks (Q3W) in 62 patients with different types of cancers has achieved promising results (104). There were $24 \%$ of patients experiencing high-grade toxicities but no treatment-related 
TABLE 1 | Clinical trials for the potential drugs targeting the IDO1/TDO-KYN pathway.

\begin{tabular}{|c|c|c|c|c|c|}
\hline Indication & Tumor type & Combination & Status & ClinicalTrials.gov & Phase \\
\hline \multirow{15}{*}{$\begin{array}{l}\text { IDO inhibitor: } \\
\text { Epacadostat }\end{array}$} & Metastatic NSCLC & Pembrolizumab & Complete & NCT03322540 & $\|$ \\
\hline & Metastatic NSCLC & $\begin{array}{l}\text { Pembrolizumab and } \\
\text { Platinum-based } \\
\text { Chemotherapy }\end{array}$ & Completed & NCT03322566 & $\|$ \\
\hline & NSCLC & Nivolumab & Terminated & NCT03348904 & III \\
\hline & Extensive Stage Small Cell Lung Cancer & Pembrolizumab & Withdrawn & NCT03402880 & $\|$ \\
\hline & NSCLC, UC & Atezolizumab & Terminated & NCT02298153 & 1 \\
\hline & Advanced Solid Tumor, NSCLC & Sirolimus & Recruiting & NCT03217669 & 1 \\
\hline & Solid Tumor, Advanced Malignancies, Metastatic Cancer & $\begin{array}{l}\text { Azacitidine and } \\
\text { Pembrolizumab }\end{array}$ & Completed & NCT02959437 & $|/| \mid$ \\
\hline & Solid Tumor, Head and Neck Cancer, Lung Cancer, UC & $\begin{array}{l}\text { Durvalumab } \\
\text { (MEDI4736) }\end{array}$ & Completed & NCT02318277 & $\mid / I I$ \\
\hline & $\begin{array}{l}\text { B-cell Malignancies, CRC, Head and Neck Cancer, LC, Lymphoma, Melanoma, } \\
\text { Ovarian Cancer, Glioblastoma }\end{array}$ & Nivolumab & Completed & NCT02327078 & $\mid / I I$ \\
\hline & $\begin{array}{l}\text { Microsatellite-instability High CRC, Endometrial Cancer, Head and Neck Cancer, } \\
\text { HCC, GC, Lung Cancer, Lymphoma, RCC, Ovarian Cancer, Solid Tumor, UC, } \\
\text { Melanoma, Bladder Cancer, TNBC }\end{array}$ & Pembrolizumab & $\begin{array}{l}\text { Active, not } \\
\text { recruiting }\end{array}$ & NCT02178722 & $|/| \mid$ \\
\hline & NSCLC & $\begin{array}{l}\text { Pembrolizumab and } \\
\text { chemotherapy }\end{array}$ & Completed & NCT02862457 & 1 \\
\hline & Solid Tumor & $\begin{array}{l}\text { INCB001158 and } \\
\text { Pembrolizumab }\end{array}$ & Terminated & NCT03361228 & $|/| \mid$ \\
\hline & Advanced Malignancies, Metastatic Cancer & $\begin{array}{l}\text { INCAGN01876 and } \\
\text { Immune Therapies }\end{array}$ & Completed & NCT03277352 & $|/| \mid$ \\
\hline & Solid Tumor & $\begin{array}{l}\text { Pembrolizumab and } \\
\text { Chemotherapy }\end{array}$ & Completed & NCT03085914 & $\mid / I 1$ \\
\hline & Solid Tumor & $\begin{array}{l}\text { Nivolumab and } \\
\text { Immune Therapies }\end{array}$ & $\begin{array}{l}\text { Active, not } \\
\text { recruiting }\end{array}$ & NCT03347123 & $|/| \mid$ \\
\hline $\begin{array}{l}\text { IDO inhibitor: } \\
\text { Navoximod }\end{array}$ & Advanced solid tumor & - & Completed & NCT02048709 & 1 \\
\hline \multirow[t]{2}{*}{$\begin{array}{l}\text { IDO inhibitor: } \\
\text { BMS-986205 }\end{array}$} & NSCLC & $\begin{array}{l}\text { Nivolumab and } \\
\text { Chemotherapy }\end{array}$ & Withdrawn & NCT03417037 & III \\
\hline & Advanced Cancer, Melanoma, NSCLC & $\begin{array}{l}\text { Nivolumab and } \\
\text { Ipilimumab }\end{array}$ & Recruiting & NCT02658890 & $|/| \mid$ \\
\hline $\begin{array}{l}\text { IDO inhibitor: MK- } \\
7162\end{array}$ & Advanced solid tumor & Pembrolizumab & Recruiting & NCT03364049 & 1 \\
\hline $\begin{array}{l}\text { IDO inhibitor: } \\
\text { LY3381916 }\end{array}$ & LY3381916 alone or in combination with LY3300054 in solid tumors & LY3300054 & Recruiting & NCT03343613 & 1 \\
\hline $\begin{array}{l}\text { IDO inhibitor: } \\
\text { KHK2455 }\end{array}$ & Locally advanced or metastatic solid tumors & Mogamulizumab & Recruiting & NCT02867007 & 1 \\
\hline \multirow{3}{*}{$\begin{array}{l}\text { IDO pathway } \\
\text { modulator: } \\
\text { Indoximod (D-1- } \\
\text { MT) }\end{array}$} & NSCLC, Progression of NSCLC, NSCLC Recurrent & $\begin{array}{l}\text { Tergenpumatucel-L } \\
\text { and docetaxel }\end{array}$ & $\begin{array}{l}\text { Active, not } \\
\text { recruiting }\end{array}$ & NCT02460367 & 1 \\
\hline & Metastatic or refractory solid tumors & $\mathrm{N} / \mathrm{A}$ & Completed & NCT00567931 & 1 \\
\hline & Relapsed or Refractory Solid Tumors & - & Terminated & NCT00739609 & 1 \\
\hline $\begin{array}{l}\text { IDO pathway } \\
\text { modulator: NLG- } \\
802\end{array}$ & Advanced solid tumors & $\mathrm{N} / \mathrm{A}$ & Recruiting & NCT03164603 & I \\
\hline \multirow[t]{2}{*}{$\begin{array}{l}\text { Dual IDO1/TDO } \\
\text { inhibitor: HTI1090/ } \\
\text { SHR9146 }\end{array}$} & Advanced solid tumors & $\begin{array}{l}\text { SHR-1210 and } \\
\text { apatinib }\end{array}$ & $\begin{array}{l}\text { Not yet } \\
\text { recruiting }\end{array}$ & NCT03491631 & 1 \\
\hline & Advanced solid tumors & $\mathrm{N} / \mathrm{A}$ & Recruiting & NCT03208959 & 1 \\
\hline $\begin{array}{l}\text { IDO Peptide } \\
\text { Vaccination }\end{array}$ & NSCLC & - & Completed & NCT01219348 & 1 \\
\hline
\end{tabular}

Data accessed from https://www.clinicaltrials.gov/ on January 15, 2021. UC, urothelial cancer; CRC, colorectal cancer; HCC, hepatocellular carcinoma; RCC, renal carcinoma; N/A, not applicable.

death and 12 out of 22 patients obtained objective responses. Unfortunately, a further phase III clinical trial with epacadostat $100 \mathrm{mg}$ twice a day (BID) and pembrolizumab $200 \mathrm{mg}$ (Q3W) failed to improve progression-free survival (PFS) in patients with metastatic melanoma (105). Because of the limitations of this trial, further clinical trials are necessary to test its therapeutic efficacy and safety.

The phase I ECHO-110 study was designed to test epacadostat at different doses combined with atezolizumab (i.e., an anti-PD-L1 agent) 1,200 mg Q3W in 29 patients with 
stage IIIB/IV NSCLC, who had previously been treated with $\geq 1$ prior line of platinum-based chemotherapy ( $\geq 2$ cycles), but not with checkpoint/IDO inhibitors. Similarly, 7 out of 29 patients displayed high-grade toxicities but no treatment-related death. Epacadostat at a dose up to $300 \mathrm{mg}$ BID combined with atezolizumab 1,200 mg Q3W was well-tolerated in patients with previously treated NSCLC (103). However, only one patient achieved objective response. The low therapeutic efficacy may stem from the fact of almost all patients with negative PD-L1 expression. Similarly, the single-arm combination of the ECHO-301 trial also failed, lining with the results from other Phase II and III trials conducted in different settings (17) and was converted into the randomized phase II trials of epacadostat combined with pembrolizumab in LC patients. In addition, the KEYNOTE-715-06/ECHO-306-06 trials with the combination of epacadostat, pembrolizumab, and platinum-based chemotherapy did not obtain promising benefit in overall response rate in NSCLC patients (Clinicaltrial.gov.). These observations suggest that the combination of Epacadostat and a PD-1/PD-L1 blockade may not be valuable for patients with PD-L1 negative LC. However, whether this treatment strategy can achieve positive responses in PD-L1 expressing NSCLC or whether combination with platinum-based chemotherapy can achieve a better outcome in NSCLC patients has not been clarified. The ongoing, randomized, phase 2 ECHO-305 (NCT03322540) and ECHO-306 (NCT03322566) trials may give promising results.

New IDO inhibitors, such as navoximod (NLG-919/GDC-0919) and BMS-986205, are also being tested in clinical trials (106). In a phase I study of the IDO1 inhibitor, combination of navoximod and atezolizumab displayed acceptable safety, tolerability, and pharmacokinetics, but not clear beneficial evidence of navoximod in patients with advanced solid tumors (107).

There are questions on whether epacadostat doses used in the ECHO-301 trial could effectively inhibit IDO1 activity in the tumor microenvironment and whether targeting multiple enzymes in the KYN pathway to control Try metabolism would benefit to these patients (58).

There are also ongoing trials testing IDO1 and TDO dual inhibitors such as HTI-1090 (SHR9146) as a monotherapy for solid tumors (NCT03208959). The dual inhibitor of DN1406131 is being tested for its safety in healthy subjects (NCT03641794) while RG70099 from Curadev/Roche is still in preclinical development (108).

In a word, most researchers have focused on IDO/TDO inhibitors for the treatment of LC, and some of them have already been tested in clinical trials. However, the current therapeutic efficacy appears limited. Thus, further studies are necessary to understand the biological functions of Try and its metabolites in the development and progression of LC. Given that the KYN downstream metabolites have profound functions in regulating $\mathrm{T}$ cell immunity against LC, these metabolites and their catalyzing enzymes may be explored for development of therapies for LC. Similarly, combination of IDO/TDO inhibitors and other therapies (chemotherapy, radiotherapy, targeted therapy, and immunotherapy) should be pursued to determine the safety and therapeutic efficacy in LC. Previous studies have demonstrated that patient's metabolism (BMI variation and hypercholesterolemia) has a significant impact on the outcome of PD1 inhibitor treatment in LC patients $(109,110)$. Some drugs can regulate body metabolism and are significantly related to clinical outcomes of ICI treatment in LC patients $(111,112)$. Metformin, an effective agent for the management of type 2 diabetes mellitus, in combination with ICI treatment can improve the anticancer effects of ICIs $(113,114)$. Statins can inhibit cholesterol production (115) and is associated with better clinical outcome of anti-PD1 treatment in advanced NSCLC patients in an intensity-dependent manner (111). However, IDO1 as an immune checkpoint is not as well studied as PD1, and the role of patient metabolism and drugs involved in its regulation on the outcome of patients treated with IDO/TDO inhibitors needs to be further confirmed. If demonstrated, IDO/TDO inhibitors may benefit many patients with LC.

\section{CONCLUSION}

Currently, modulation of Try metabolism has been used for diagnosis, prognosis, and therapies for LC. The levels of circulating IDO activity and downstream metabolites (3-HAA, $\mathrm{QA}, \mathrm{KA}$, etc.) can be used to predict the efficacy of different treatments in $\operatorname{LC}(116,117)$. However, the results are inconsistent, which may be caused by limitations, such as small sample size, inconsistent measurement methods, influence of the gender, tumor stage, and tumor heterogeneity. Hence, further studies are needed in multi-centers with a larger population, standardized measurement methods, paired samples, and detailed analysis for different stages and pathological types of LC. Currently, some metabolites, enzyme inhibitors targeting immune checkpoints, and modulators have been developed for the diagnosis and treatment of LC. Because the change in metabolomics is one of the factors for the development of cancer, it will be wise to integrate the role of metabolomic changes in the pathogenesis of LC and consider other factors together for the development of therapeutic strategies for LC. Therefore, further studies are necessary to understand the process of complicated Try metabolism and its regulation in different types and stages of LC.

\section{AUTHOR CONTRIBUTIONS}

CL performed the literature search and drafted the manuscript and figures. HZ edited and revised the manuscript. All authors contributed to the article and approved the submitted version.

\section{FUNDING}

This work was supported by grants from the National Natural Science Foundation of China 81703087, the United Fund of the Second Hospital of Dalian Medical University and Dalian Institute of Chemical Physics, Chinese Academy of Sciences (UF-ZD-202011), and the Project of Education Department of Liaoning Province (LZ2020009). 


\section{REFERENCES}

1. Siegel RL, Miller KD, Fuchs HE, Jemal A. Cancer Statistics, 2021. CA: A Cancer J Clin (2021) 71(1):7-33. doi: 10.3322/caac.21654

2. Tan DS, Yom SS, Tsao MS, Pass HI, Kelly K, Peled N, et al. The International Association for the Study of Lung Cancer Consensus Statement on Optimizing Management of EGFR Mutation-Positive Non-Small Cell Lung Cancer: Status in 2016. J Thorac Oncol (2016) 11:946-63. doi: 10.1016/j.jtho.2016.05.008

3. Antonio M, Lara F, Sara M, Maria GS, Luigi G, Antonio C, et al. Clinical Features and Outcome of Patients With Non-Small-Cell Lung Cancer Harboring BRAF Mutations. J Clin Oncol (2011) 29(26):3574-9. doi: 10.1200/JCO.2011.35.9638

4. Jänne PA, Shaw AT, Pereira JR, Jeannin G, Vansteenkiste J, Barrios C, et al. Selumetinib Plus Docetaxel for KRAS -Mutant Advanced Non-Small-Cell Lung Cancer: A Randomised, Multicentre, Placebo-Controlled, Phase 2 Study. Lancet Oncol (2013) 14(1):38-47. doi: 10.1016/S1470-2045(12) 70489-8

5. Rosell R, Carcereny E, Gervais R, Vergnenegre A, Massuti B, Felip E, et al. Erlotinib Versus Standard Chemotherapy as First-Line Treatment for European Patients With Advanced EGFR Mutation-Positive Non-SmallCell Lung Cancer (EURTAC): A Multicentre, Open-Label, Randomised Phase 3 Trial. Lancet Oncol (2012) 13(3):239-46. doi: 10.1016/S1470-2045 (11)70393-X

6. A JP, Chih-Hsin YJ, Dong-Wan K, David P, Yuichiro O, S RS, et al. AZD9291 in EGFR Inhibitor-Resistant Non-Small-Cell Lung Cancer. N Engl J Med (2015) 372(18):1689-99. doi: 10.1056/NEJMoa1411817

7. Wishart DS. Is Cancer a Genetic Disease or a Metabolic Disease? EBioMedicine (2015) 2(6):478-9. doi: 10.1016/j.ebiom.2015.05.022

8. Hanahan D, Weinberg RA. Hallmarks of Cancer: The Next Generation. Cell (2011) 144:646-74. doi: 10.1016/j.cell.2011.02.013

9. Burk D, Schade AL. On Respiratory Impairment in Cancer Cells. Science (1956) 124:270-2. doi: 10.1126/science.124.3215.267

10. Fahrmann JF, Vykoukal JV, Ostrin EJ. Amino Acid Oncometabolism and Immunomodulation of the Tumor Microenvironment in Lung Cancer. Front Oncol (2020) 10:276. doi: 10.3389/fonc.2020.00276

11. Godin-Ethier J, Hanafi LA, Piccirillo CA, Lapointe R. Indoleamine 2,3Dioxygenase Expression in Human Cancers: Clinical and Immunologic Perspectives. Clin Cancer Res (2011) 17:6985-91. doi: 10.1158/10780432.CCR-11-1331

12. Weljie AM, Jirik FR. Hypoxia-Induced Metabolic Shifts in Cancer Cells: Moving Beyond the Warburg Effect. Int J Biochem Cell Biol (2011) 43:981-9. doi: 10.1016/j.biocel.2010.08.009

13. Pardridge WM. Tryptophan Transport Through the Blood-Brain Barrier: In Vivo Measurement of Free and Albumin-Bound Amino Acid. Life Sci (1979) 25(17):1519-28. doi: 10.1016/0024-3205(79)90378-3

14. Cervenka I, Agudelo LZ, Ruas JL. Kynurenines: Tryptophan's Metabolites in Exercise, Inflammation, and Mental Health. Science (2017) 357(6349): eaaf9794. doi: 10.1126/science.aaf9794

15. Schwarcz R, Stone TW. The Kynurenine Pathway and the Brain: Challenges, Controversies and Promises. Neuropharmacology (2017) 112:237-47. doi: 10.1016/j.neuropharm.2016.08.003

16. Munn DH, Mellor AL. IDO in the Tumor Microenvironment: Inflammation, Counter-Regulation, and Tolerance. Trends Immunol (2016) 37:193-207. doi: 10.1016/j.it.2016.01.002

17. Platten M, Nollen EAA, Röhrig UF, Fallarino F, Opitz CA. Tryptophan Metabolism as a Common Therapeutic Target in Cancer, Neurodegeneration and Beyond. Nat Rev Drug Discov (2019) 18(5):379401. doi: 10.1038/s41573-019-0016-5

18. Dai $\mathrm{X}$, Zhu BT. Indoleamine 2,3-Dioxygenase Tissue Distribution and Cellular Localization in Mice: Implications for Its Biological Functions. J Histochem Cytochem (2010) 58:17-28. doi: 10.1369/jhc.2009.953604

19. Yoshida R, Imanishi J, Oku T, Kishida T, Hayaishi O. Induction of Pulmonary Indoleamine 2,3-Dioxygenase by Interferon. Proc Natl Acad Sci USA (1981) 78:129-32. doi: 10.1073/pnas.78.1.129

20. Yoshida R, Urade Y, Tokuda M, Hayaishi O. Induction of Indoleamine 2,3Dioxygenase in Mouse Lung During Virus Infection. Proc Natl Acad Sci USA (1979) 76:4084-6. doi: 10.1073/pnas.76.8.4084
21. Miyagi Y, Higashiyama M, Gochi A, Akaike M, Ishikawa T, Miura T, et al. Plasma Free Amino Acid Profiling of Five Types of Cancer Patients and Its Application for Early Detection. PLoS One (2011) 6:e24143. doi: 10.1371/ journal.pone.0024143

22. Weckwerth W, Morgenthal K. Metabolomics: From Pattern Recognition to Biological Interpretation. Drug Discov Today (2005) 10:1551-8. doi: 10.1016/S1359-6446(05)03609-3

23. Karayama M, Masuda J, Mori K, Yasui H, Hozumi H, Suzuki Y, et al. Comprehensive Assessment of Multiple Tryptophan Metabolites as Potential Biomarkers for Immune Checkpoint Inhibitors in Patients With Non-Small Cell Lung Cancer. Clin Transl Oncol (2021) 23(2):418-23. doi: 10.1007/s12094-020-02421-8

24. Ren YP, Tang AG, Zhou QX, Xiang ZY. Clinical Significance of Simultaneous Determination of Serum Tryptophan and Tyrosine in Patients With Lung Cancer. J Clin Lab Anal (2011) 25:246-50. doi: $10.1002 /$ jcla.20467

25. Miyamoto S, Taylor SL, Barupal DK, Taguchi A, Wohlgemuth G, Wikoff WR, et al. Systemic Metabolomic Changes in Blood Samples of Lung Cancer Patients Identified by Gas Chromatography Time-of-Flight Mass Spectrometry. Metabolites (2015) 5:192-210. doi: 10.3390/metabo5020192

26. Nguyen DJM, Theodoropoulos G, Li YY, Wu C, Sha W, Feun LG, et al. Targeting the Kynurenine Pathway for the Treatment of Cisplatin-Resistant Lung Cancer. Mol Cancer Res (2020) 18:105-17. doi: 10.1158/15417786.MCR-19-0239

27. Munn DH, Mellor AL. Indoleamine 2,3-Dioxygenase and Tumor-Induced Tolerance. J Clin Invest (2007) 117:1147-54. doi: 10.1172/JCI31178

28. Pisters PW, Pearlstone DB. Protein and Amino Acid Metabolism in Cancer Cachexia: Investigative Techniques and Therapeutic Interventions. Crit Rev Clin Lab Sci (1993) 30:223-72. doi: 10.3109/10408369309084669

29. Shingyoji M, Iizasa T, Higashiyama M, Imamura F, Saruki N, Imaizumi A, et al. The Significance and Robustness of a Plasma Free Amino Acid (PFAA) Profile-Based Multiplex Function for Detecting Lung Cancer. BMC Cancer (2013) 13:77. doi: 10.1186/1471-2407-13-77

30. Jun M, Masahiko H, Akira I, Tomio N, Hiroshi Y, Takashi D, et al. Possibility of Multivariate Function Composed of Plasma Amino Acid Profiles as a Novel Screening Index for Non-Small Cell Lung Cancer: A Case Control Study. BMC Cancer (2010) 10:690. doi: 10.1186/1471-2407-10-690

31. Kim HJ, Jang SH, Ryu JS, Lee JE, Kim YC, Lee MK, et al. The Performance of a Novel Amino Acid Multivariate Index for Detecting Lung Cancer: A Case Control Study in Korea. Lung Cancer (2015) 90:522-7. doi: 10.1016/ j.lungcan.2015.10.006

32. Ruiying C, Zeyun L, Yongliang Y, Zijia Z, Ji Z, Xin T, et al. A Comprehensive Analysis of Metabolomics and Transcriptomics in Non-Small Cell Lung Cancer. PLoS One (2020) 15:e0232272. doi: 10.1371/journal.pone.0232272

33. Munn DH, Sharma MD, Lee JR, Jhaver KG, Johnson TS, Keskin DB, et al. Potential Regulatory Function of Human Dendritic Cells Expressing Indoleamine 2,3-Dioxygenase. Science (2002) 297:1867-70. doi: 10.1126/ science. 1073514

34. Theate I, van Baren N, Pilotte L, Moulin P, Larrieu P, Renauld JC, et al. Extensive Profiling of the Expression of the Indoleamine 2,3-Dioxygenase 1 Protein in Normal and Tumoral Human Tissues. Cancer Immunol Res (2015) 3:161-72. doi: 10.1158/2326-6066.CIR-14-0137

35. Wang Y, Liu H, McKenzie G, Witting PK, Stasch JP, Hahn M, et al. Kynurenine Is an Endothelium-Derived Relaxing Factor Produced During Inflammation. Nat Med (2010) 16:279-85. doi: 10.1038/nm.2092

36. Karanikas V, Zamanakou M, Kerenidi T, Dahabreh J, Hevas A, Nakou M, et al. Indoleamine 2,3-Dioxygenase (IDO) Expression in Lung Cancer. Cancer Biol Ther (2007) 6:1258-62. doi: 10.4161/cbt.6.8.4446

37. Suzuki Y, Suda T, Furuhashi K, Suzuki M, Fujie M, Hahimoto D, et al. Increased Serum Kynurenine/Tryptophan Ratio Correlates With Disease Progression in Lung Cancer. Lung Cancer (2010) 67:361-5. doi: 10.1016/ j.lungcan.2009.05.001

38. Chuang SC, Fanidi A, Ueland PM, Relton C, Midttun O, Vollset SE, et al. Circulating Biomarkers of Tryptophan and the Kynurenine Pathway and Lung Cancer Risk. Cancer Epidemiol Biomarkers Prev (2014) 23:461-8. doi: 10.1158/1055-9965.EPI-13-0770

39. Huang JY, Larose TL, Luu HN, Wang R, Fanidi A, Alcala K, et al. Circulating Markers of Cellular Immune Activation in Prediagnostic Blood Sample and 
Lung Cancer Risk in the Lung Cancer Cohort Consortium (Lc3). Int J Cancer (2020) 146:2394-405. doi: 10.1002/ijc.32555

40. Tang D, Yue L, Yao R, Zhou L, Yang Y, Lu L, et al. P53 Prevent Tumor Invasion and Metastasis by Down-Regulating IDO in Lung Cancer. Oncotarget (2017) 8:54548-57. doi: 10.18632/oncotarget.17408

41. Levina V, Su Y, Gorelik E. Immunological and Nonimmunological Effects of Indoleamine 2,3-Dioxygenase on Breast Tumor Growth and Spontaneous Metastasis Formation. Clin Dev Immunol (2012) 2012:173029. doi: 10.1155/ 2012/173029

42. Smith C, Chang MY, Parker KH, Beury DW, DuHadaway JB, Flick HE, et al. IDO Is a Nodal Pathogenic Driver of Lung Cancer and Metastasis Development. Cancer Discov (2012) 2(8):722-35. doi: 10.1158/2159-8290.CD-12-0014

43. Schafer CC, Wang Y, Hough KP, Sawant A, Grant SC, Thannickal VJ, et al. Indoleamine 2,3-Dioxygenase Regulates Anti-Tumor Immunity in Lung Cancer by Metabolic Reprogramming of Immune Cells in the Tumor Microenvironment. Oncotarget (2016) 7:75407-24. doi: 10.18632/ oncotarget.12249

44. Agullo-Ortuno MT, Gomez-Martin O, Ponce S, Iglesias L, Ojeda L, Ferrer I, et al. Blood Predictive Biomarkers for Patients With Non-Small-Cell Lung Cancer Associated With Clinical Response to Nivolumab. Clin Lung Cancer (2020) 21:75-85. doi: 10.1016/j.cllc.2019.08.006

45. Uyttenhove C, Pilotte L, Theate I, Stroobant V, Colau D, Parmentier N, et al. Evidence for a Tumoral Immune Resistance Mechanism Based on Tryptophan Degradation by Indoleamine 2,3-Dioxygenase. Nat Med (2003) 9:1269-74. doi: 10.1038/nm934

46. Zamanakou M, Germenis AE, Karanikas V. Tumor Immune Escape Mediated by Indoleamine 2,3-Dioxygenase. Immunol Lett (2007) 111:6975. doi: 10.1016/j.imlet.2007.06.001

47. Wang Y, Hu GF, Wang ZH. The Status of Immunosuppression in Patients With Stage IIIB or IV Non-Small-Cell Lung Cancer Correlates With the Clinical Characteristics and Response to Chemotherapy. Onco Targets Ther (2017) 10:3557-66. doi: 10.2147/OTT.S136259

48. Wang W, Huang L, Jin JY, Pi W, Ellsworth SG, Jolly S, et al. A Validation Study on IDO Immune Biomarkers for Survival Prediction in Non-Small Cell Lung Cancer: Radiation Dose Fractionation Effect in Early-Stage Disease. Clin Cancer Res (2020) 26:282-9. doi: 10.1158/1078-0432.CCR-19-1202

49. Botticelli A, Mezi S, Pomati G, Cerbelli B, Cerbelli E, Roberto M, et al. Tryptophan Catabolism as Immune Mechanism of Primary Resistance to Anti-PD-1. Front Immunol (2020) 11:1243. doi: 10.3389/fimmu.2020.01243

50. Wang W, Huang L, Jin JY, Jolly S, Zang Y, Wu H, et al. IDO Immune Status After Chemoradiation May Predict Survival in Lung Cancer Patients. Cancer Res (2018) 78:809-16. doi: 10.1158/0008-5472.CAN-17-2995

51. Ma W, Duan H, Zhang R, Wang X, Xu H, Zhou Q, et al. High Expression of Indoleamine 2, 3-Dioxygenase in Adenosquamous Lung Carcinoma Correlates With Favorable Patient Outcome. J Cancer (2019) 10:267-76. doi: 10.7150/jca.27507

52. Löb S, Königsrainer A, Zieker D, Brücher BLDM, Rammensee H-G, Opelz G, et al. IDO1 and IDO2 Are Expressed in Human Tumors: Levo- But Not Dextro-1-Methyl Tryptophan Inhibits Tryptophan Catabolism. Cancer Immunol Immunother (2009) 58:153-7. doi: 10.1007/s00262-008-0513-6

53. Mandarano M, Bellezza G, Belladonna ML, Vannucci J, Gili A, Ferri I, et al. Indoleamine 2,3-Dioxygenase 2 Immunohistochemical Expression in Resected Human Non-Small Cell Lung Cancer: A Potential New Prognostic Tool. Front Immunol (2020) 11:839. doi: 10.3389/fimmu. 2020.00839

54. Witkiewicz AK, Costantino CL, Metz R, Muller AJ, Prendergast GC, Yeo CJ, et al. Genotyping and Expression Analysis of IDO2 in Human Pancreatic Cancer: A Novel, Active Target. J Am Coll Surg (2009) 208(5):781-7. doi: 10.1016/j.jamcollsurg.2008.12.018

55. Michael P, Nikolaus VKD, Iris O, Wolfgang W, Katharina O. Cancer Immunotherapy by Targeting IDO1/TDO and Their Downstream Effectors. Front Immunol (2015) 5:673. doi: 10.3389/fimmu.2014.00673

56. Yuasa HJ, Mizuno K, Ball HJ. Low Efficiency IDO2 Enzymes Are Conserved in Lower Vertebrates, Whereas Higher Efficiency IDO1 Enzymes Are Dispensable. FEBS J (2015) 282:2735-45. doi: 10.1111/febs.13316

57. Fatokun AA, Hunt NH, Ball HJ. Indoleamine 2,3-Dioxygenase 2 (IDO2) and the Kynurenine Pathway: Characteristics and Potential Roles in Health and Disease. Amino Acids (2013) 45:1319-29. doi: 10.1007/s00726-013-1602-1
58. Yuasa HJ, Ball HJ, Ho YF, Austin CJ, Whittington CM, Belov K, et al. Characterization and Evolution of Vertebrate Indoleamine 2, 3-Dioxygenases IDOs From Monotremes and Marsupials. Comp Biochem Physiol B Biochem Mol Biol (2009) 153:137-44. doi: 10.1016/j.cbpb.2009.02.002

59. Jusof FF, Bakmiwewa SM, Weiser S, Too LK, Metz R, Prendergast GC, et al. Investigation of the Tissue Distribution and Physiological Roles of Indoleamine 2,3-Dioxygenase-2. Int J Tryptophan Res (2017) 10:1178646917735098. doi: 10.1177/1178646917735098

60. Cheong JE, Sun L. Targeting the IDO1/TDO2-KYN-AhR Pathway for Cancer Immunotherapy - Challenges and Opportunities. Trends Pharmacol Sci (2018) 39:307-25. doi: 10.1016/j.tips.2017.11.007

61. Moon PK, Tran S, Minhas PS. Revisiting IDO and Its Value As a Predictive Marker for Anti-PD-1 Resistance. J Transl Med (2019) 17:31. doi: 10.1186/ s12967-019-1784-8

62. Platten M, Wick W, Van den Eynde BJ. Tryptophan Catabolism in Cancer: Beyond IDO and Tryptophan Depletion. Cancer Res (2012) 72:5435-40. doi: 10.1158/0008-5472.CAN-12-0569

63. Nicolas VB, Van den Eynde BJ. Tumoral Immune Resistance Mediated by Enzymes That Degrade Tryptophan. Cancer Immunol Res (2015) 3(9):97885. doi: 10.1158/2326-6066.CIR-15-0095

64. Opitz CA, Litzenburger UM, Sahm F, Ott M, Tritschler I, Trump S, et al. An Endogenous Tumour-Promoting Ligand of the Human Aryl Hydrocarbon Receptor. Nature (2011) 478:197-203. doi: 10.1038/nature10491

65. Wikoff WR, Grapov D, Fahrmann JF, DeFelice B, Rom WN, Pass HI, et al. Metabolomic Markers of Altered Nucleotide Metabolism in Early Stage Adenocarcinoma. Cancer Prev Res (Phila) (2015) 8:410-8. doi: 10.1158/ 1940-6207.CAPR-14-0329

66. Novikov O, Wang Z, Stanford EA, Parks AJ, Ramirez-Cardenas A, Landesman E, et al. An Aryl Hydrocarbon Receptor-Mediated Amplification Loop That Enforces Cell Migration in ER-/PR-/Her2Human Breast Cancer Cells. Mol Pharmacol (2016) 90:674-88. doi: 10.1124/mol.116.105361

67. Yamasuge W, Yamamoto Y, Fujigaki H, Hoshi M, Nakamoto K, Kunisawa $\mathrm{K}$, et al. Indoleamine 2,3-Dioxygenase 2 Depletion Suppresses Tumor Growth in a Mouse Model of Lewis Lung Carcinoma. Cancer Sci (2019) 110:3061-7. doi: 10.1111/cas.14179

68. Hsu YL, Hung JY, Chiang SY, Jian SF, Wu CY, Lin YS, et al. Lung CancerDerived Galectin-1 Contributes to Cancer Associated Fibroblast-Mediated Cancer Progression and Immune Suppression Through TDO2/kynurenine Axis. Oncotarget (2016) 7:27584-98. doi: 10.18632/oncotarget.8488

69. Liu Y, Xu P, Liu H, Fang C, Guo H, Chen X, et al. Silencing IDO2 in Dendritic Cells: A Novel Strategy to Strengthen Cancer Immunotherapy in a Murine Lung Cancer Model. Int J Oncol (2020) 57:587-97. doi: 10.3892/ ijo. 2020.5073

70. Luo J, Solimini NL, Elledge SJ. Principles of Cancer Therapy: Oncogene and Non-Oncogene Addiction. Cell (2009) 136:823-37. doi: 10.1016/ j.cell.2009.02.024

71. Prendergast GC. Immune Escape as a Fundamental Trait of Cancer: Focus on IDO. Oncogene (2008) 27(28):3889-900. doi: 10.1038/onc.2008.35

72. Jiang X, Wang J, Deng X, Xiong F, Ge J, Xiang B, et al. Role of the Tumor Microenvironment in PD-L1/PD-1-Mediated Tumor Immune Escape. Mol Cancer (2019) 18:10. doi: 10.1186/s12943-018-0928-4

73. Mellor AL, Munn DH. IDO Expression by Dendritic Cells: Tolerance and Tryptophan Catabolism. Nat Rev Immunol (2004) 4:762-74. doi: 10.1038/ nril457

74. Munn DH, Sharma MD, Baban B, Harding HP, Zhang Y, Ron D, et al. GCN2 Kinase in T Cells Mediates Proliferative Arrest and Anergy Induction in Response to Indoleamine 2,3-Dioxygenase. Immunity (2005) 22:633-42. doi: 10.1016/j.immuni.2005.03.013

75. Rodriguez PC, Quiceno DG, Ochoa AC. L-Arginine Availability Regulates T-Lymphocyte Cell-Cycle Progression. Blood (2007) 109:1568-73. doi: 10.1182/blood-2006-06-031856

76. Ravishankar B, Liu H, Shinde R, Chaudhary K, Xiao W, Bradley J, et al. The Amino Acid Sensor GCN2 Inhibits Inflammatory Responses to Apoptotic Cells Promoting Tolerance and Suppressing Systemic Autoimmunity. Proc Natl Acad Sci USA (2015) 112:10774-9. doi: 10.1073/pnas.1504276112

77. Fallarino F, Grohmann U, You S, McGrath BC, Cavener DR, Vacca C, et al. The Combined Effects of Tryptophan Starvation and Tryptophan 
Catabolites Down-Regulate T Cell Receptor Zeta-Chain and Induce a Regulatory Phenotype in Naive T Cells. J Immunol (2006) 176:6752-61. doi: 10.4049/jimmunol.176.11.6752

78. Liu H, Huang L, Bradley J, Liu K, Bardhan K, Ron D, et al. GCN2-Dependent Metabolic Stress Is Essential for Endotoxemic Cytokine Induction and Pathology. Mol Cell Biol (2014) 34(3):428-38. doi: 10.1128/MCB.00946-13

79. Sonner JK, Deumelandt K, Ott M, Thomé CM, Rauschenbach KJ, Schulz S, et al. The Stress Kinase GCN2 Does Not Mediate Suppression of Antitumor T Cell Responses by Tryptophan Catabolism in Experimental Melanomas. OncoImmunology (2016) 5(12):e1240858. doi: 10.1080/2162402X.2016.1240858

80. Castilho BA, Shanmugam R, Silva RC, Ramesh R, Himme BM, Sattlegger E. Keeping the Eif2 Alpha Kinase Gcn2 in Check. BBA - Mol Cell Res (2014) 1843(9):1948-68. doi: 10.1016/j.bbamcr.2014.04.006

81. Metz R, Rust S, DuHadaway JB, Mautino MR, Munn DH, Vahanian NN, et al. IDO Inhibits a Tryptophan Sufficiency Signal That Stimulates mTOR: A Novel IDO Effector Pathway Targeted by D-1-Methyl-Tryptophan. OncoImmunology (2012) 1(9):1460-8. doi: 10.4161/onci.21716

82. Cobbold SP, Adams E, Farquhar CA, Nolan KF, Howie D, Lui KO, et al. Infectious Tolerance via the Consumption of Essential Amino Acids and mTOR Signaling. Proc Natl Acad Sci USA (2009) 106:12055-60. doi: 10.1073/pnas.0903919106

83. Johnson TS, Munn DH. Host Indoleamine 2,3-Dioxygenase: Contribution to Systemic Acquired Tumor Tolerance. Immunol Invest (2012) 41:765-97. doi: 10.3109/08820139.2012.689405

84. Mezrich JD, Fechner JH, Zhang X, Johnson BP, Burlingham WJ, Bradfield CA. An Interaction Between Kynurenine and the Aryl Hydrocarbon Receptor can Generate Regulatory T Cells. J Immunol (Baltimore Md.: 1950) (2010) 185(6):3190-8. doi: 10.4049/jimmunol.0903670

85. Quintana FJ, Murugaiyan G, Farez MF, Mitsdoerffer M, Tukpah AM, Burns EJ, et al. An Endogenous Aryl Hydrocarbon Receptor Ligand Acts on Dendritic Cells and T Cells to Suppress Experimental Autoimmune Encephalomyelitis. Proc Natl Acad Sci USA (2010) 107:20768-73. doi: 10.1073/pnas.1009201107

86. Jaronen M, Quintana FJ. Immunological Relevance of the Coevolution of IDO1 and AHR. Front Immunol (2014) 5:521. doi: 10.3389/fimmu.2014.00521

87. Manlapat AK, Kahler DJ, Chandler PR, Munn DH, Mellor AL. CellAutonomous Control of Interferon Type I Expression by Indoleamine 2,3Dioxygenase in Regulatory CD19+ Dendritic Cells. Eur J Immunol (2007) 37:1064-71. doi: 10.1002/eji.200636690

88. Fallarino F, Grohmann U, Vacca C, Bianchi R, Orabona C, Spreca A, et al. T Cell Apoptosis by Tryptophan Catabolism. Cell Death Differ (2002) 9:106977. doi: $10.1038 /$ sj.cdd. 4401073

89. Frumento G, Rotondo R, Tonetti M, Damonte G, Benatti U, Ferrara GB. Tryptophan-Derived Catabolites Are Responsible for Inhibition of $\mathrm{T}$ and Natural Killer Cell Proliferation Induced by Indoleamine 2,3-Dioxygenase. J Exp Med (2002) 196:459-68. doi: 10.1084/jem.20020121

90. Gargaro M, Vacca C, Massari S, Scalisi G, Manni G, Mondanelli G, et al. Engagement of Nuclear Coactivator 7 by 3-Hydroxyanthranilic Acid Enhances Activation of Aryl Hydrocarbon Receptor in Immunoregulatory Dendritic Cells. Front Immunol (2019) 10:1973. doi: 10.3389/fimmu.2019.01973

91. Dubinett S, Sharma S. Towards Effective Immunotherapy for Lung Cancer: Simultaneous Targeting of Tumor-Initiating Cells and Immune Pathways in the Tumor Microenvironment. Immunotherapy (2009) 1:721-5. doi: $10.2217 / \mathrm{imt} .09 .56$

92. Halak BK, Maguire HCJr, Lattime EC. Tumor-Induced Interleukin-10 Inhibits Type 1 Immune Responses Directed at a Tumor Antigen as Well as a NonTumor Antigen Present at the Tumor Site. Cancer Res (1999) 59(4):911-7.

93. Labadie BW, Bao R, Luke JJ. Reimagining IDO Pathway Inhibition in Cancer Immunotherapy via Downstream Focus on the Tryptophan-KynurenineAryl Hydrocarbon Axis. Clin Cancer Res (2019) 25:1462-71. doi: 10.1158/ 1078-0432.CCR-18-2882

94. DiNatale BC, Murray IA, Schroeder JC, Flaveny CA, Lahoti TS, Laurenzana EM, et al. Kynurenic Acid Is a Potent Endogenous Aryl Hydrocarbon Receptor Ligand That Synergistically Induces Interleukin-6 in the Presence of Inflammatory Signaling. Toxicol Sci (2010) 115:89-97. doi: 10.1093/toxsci/kfq024

95. Seok SH, Ma ZX, Feltenberger JB, Chen H, Chen H, Scarlett C, et al. Trace Derivatives of Kynurenine Potently Activate the Aryl Hydrocarbon Receptor (AHR). J Biol Chem (2018) 293:1994-2005. doi: 10.1074/jbc.RA117.000631
96. Takenaka MC, Quintana FJ. Tolerogenic Dendritic Cells. Semin Immunopathol (2017) 39:113-20. doi: 10.1007/s00281-016-0587-8

97. Li Q, Harden JL, Anderson CD, Egilmez NK. Tolerogenic Phenotype of IFN$\gamma$-Induced IDO+ Dendritic Cells Is Maintained via an Autocrine IDOKynurenine/AhR-IDO Loop. J Immunol (2016) 197:962-70. doi: 10.4049/ jimmunol.1502615

98. Nguyen NT, Kimura A, Nakahama T, Chinen I, Masuda K, Nohara K, et al. Aryl Hydrocarbon Receptor Negatively Regulates Dendritic Cell Immunogenicity via a Kynurenine-Dependent Mechanism. Proc Natl Acad Sci USA (2010) 107:19961-6. doi: 10.1073/pnas.1014465107

99. Prendergast GC, Malachowski WP, DuHadaway JB, Muller AJ. Discovery of IDO1 Inhibitors: From Bench to Bedside. Cancer Res (2017) 77:6795-811. doi: 10.1158/0008-5472.CAN-17-2285

100. Liu KT, Liu YH, Liu HL, Chong IW, Yen MC, Kuo PL. Neutrophils Are Essential in Short Hairpin RNA of Indoleamine 2,3- Dioxygenase Mediated-Antitumor Efficiency. Mol Ther Nucleic Acids (2016) 5:e397. doi: 10.1038/mtna.2016.105

101. Munn DH, Mellor AL. IDO and Tolerance to Tumors. Trends Mol Med (2004) 10:15-8. doi: 10.1016/j.molmed.2003.11.003

102. Hou DY, Muller AJ, Sharma MD, DuHadaway J, Banerjee T, Johnson M, et al. Inhibition of Indoleamine 2,3-Dioxygenase in Dendritic Cells by Stereoisomers of 1-Methyl-Tryptophan Correlates With Antitumor Responses. Cancer Res (2007) 67:792-801. doi: 10.1158/0008-5472.CAN06-2925

103. Hellmann MD, Gettinger S, Chow LQM, Gordon M, Awad MM, Cha E, et al. Phase 1 Study of Epacadostat in Combination With Atezolizumab for Patients With Previously Treated Advanced Nonsmall Cell Lung Cancer. Int J Cancer (2020) 147:1963-9. doi: 10.1002/ijc.32951

104. Mitchell TC, Hamid O, Smith DC, Bauer TM, Wasser JS, Olszanski AJ, et al. Epacadostat Plus Pembrolizumab in Patients With Advanced Solid Tumors: Phase I Results From a Multicenter, Open-Label Phase I/II Trial (ECHO202/KEYNOTE-037). J Clin Oncol (2018) 36:3223-30. doi: 10.1200/ JCO.2018.78.9602

105. Muller AJ, Manfredi MG, Zakharia Y, Prendergast GC. Inhibiting IDO Pathways to Treat Cancer: Lessons From the ECHO-301 Trial and Beyond. Semin Immunopathol (2019) 41:41-8. doi: 10.1007/s00281-018-0702-0

106. Liu M, Wang X, Wang L, Ma X, Gong Z, Zhang S, et al. Targeting the IDO1 Pathway in Cancer: From Bench to Bedside. J Hematol Oncol (2018) 11:100. doi: 10.1186/s13045-018-0644-y

107. Jung KH, LoRusso P, Burris H, Gordon M, Bang YJ, Hellmann MD, et al. Phase I Study of the Indoleamine 2,3-Dioxygenase 1 (IDO1) Inhibitor Navoximod (GDC-0919) Administered With PD-L1 Inhibitor (Atezolizumab) in Advanced Solid Tumors. Clin Cancer Res (2019) 25:3220-8. doi: 10.1158/1078-0432.CCR-18-2740

108. Gyulveszi G, Fischer C, Mirolo M, Stern M, Green L, Ceppi M, et al. Abstract LB-085: RG70099: A Novel, Highly Potent Dual IDO1/TDO Inhibitor to Reverse Metabolic Suppression of Immune Cells in the Tumor MicroEnvironment. Cancer Res (2016) 76(14_Supplement):LB-085. doi: 10.1158/ 1538-7445.AM2016-LB-085

109. Cortellini A, Ricciuti B, Tiseo M, Bria E, Banna GL, Aerts JG, et al. Baseline BMI and BMI Variation During First Line Pembrolizumab in NSCLC Patients With a PD-L1 Expression $>/=50 \%$ : A Multicenter Study With External Validation. I Immunother Cancer (2020) 8(2):e001403. doi: 10.1136/jitc-2020-001403

110. Perrone F, Minari R, Bersanelli M, Bordi P, Tiseo M, Favari E, et al. The Prognostic Role of High Blood Cholesterol in Advanced Cancer Patients Treated With Immune Checkpoint Inhibitors. J Immunother (2020) 43:196203. doi: $10.1097 / \mathrm{cji} .0000000000000321$

111. Cantini L, Pecci F, Hurkmans DP, Belderbos RA, Lanese A, Copparoni C, et al. High-Intensity Statins Are Associated With Improved Clinical Activity of PD-1 Inhibitors in Malignant Pleural Mesothelioma and Advanced NonSmall Cell Lung Cancer Patients. Eur J Cancer (2021) 144:41-8. doi: 10.1016/ j.ejca.2020.10.031

112. Liu W, Wang Y, Luo J, Liu M, Luo Z. Pleiotropic Effects of Metformin on the Antitumor Efficiency of Immune Checkpoint Inhibitors. Front Immunol (2020) 11:586760. doi: 10.3389/fimmu.2020.586760

113. Afzal MZ, Dragnev K, Sarwar T, Shirai K. Clinical Outcomes in non-Small-Cell Lung Cancer Patients Receiving Concurrent Metformin and Immune Checkpoint Inhibitors. Lung Cancer Manag (2019) 8:LMT11. doi: 10.2217/lmt-2018-0016 
114. Scharping NE, Menk AV, Whetstone RD, Zeng X, Delgoffe GM. Efficacy of PD-1 Blockade Is Potentiated by Metformin-Induced Reduction of Tumor Hypoxia. Cancer Immunol Res (2017) 5:9-16. doi: 10.1158/2326-6066.Cir16-0103

115. Fatehi Hassanabad A. Current Perspectives on Statins as Potential AntiCancer Therapeutics: Clinical Outcomes and Underlying Molecular Mechanisms. Transl Lung Cancer Res (2019) 8:692-9. doi: 10.21037/ tlcr.2019.09.08

116. Prodinger J, Loacker LJ, Schmidt RL, Ratzinger F, Greiner G, Witzeneder N, et al. The Tryptophan Metabolite Picolinic Acid Suppresses Proliferation and Metabolic Activity of CD4+ T Cells and Inhibits C-Myc Activation. J Leukoc Biol (2016) 99:583-94. doi: 10.1189/jlb.3A0315-135R

117. Wirthgen E, Hoeflich A, Rebl A, Gunther J. Kynurenic Acid: The JanusFaced Role of an Immunomodulatory Tryptophan Metabolite and Its Link to Pathological Conditions. Front Immunol (2017) 8:1957. doi: 10.3389/ fimmu.2017.01957
Conflict of Interest: The authors declare that the research was conducted in the absence of any commercial or financial relationships that could be construed as a potential conflict of interest.

Publisher's Note: All claims expressed in this article are solely those of the authors and do not necessarily represent those of their affiliated organizations, or those of the publisher, the editors and the reviewers. Any product that may be evaluated in this article, or claim that may be made by its manufacturer, is not guaranteed or endorsed by the publisher.

Copyright $(02021 \mathrm{Li}$ and Zhao. This is an open-access article distributed under the terms of the Creative Commons Attribution License (CC BY). The use, distribution or reproduction in other forums is permitted, provided the original author(s) and the copyright owner(s) are credited and that the original publication in this journal is cited, in accordance with accepted academic practice. No use, distribution or reproduction is permitted which does not comply with these terms. 